\title{
PINTURA E TEATRO: A PEDAGOGIA DO OLHAR N'O TRIBOFE DE ARTHUR AZEVEDO
}

As artes são "matrizes geradoras de práticas sociais" (Pesavento, I 995, 2005) e os artistas, tais como literatos, dramaturgos e pintores, são importantes mediadores da vida social por transitarem por múltiplos planos, traduzirem códigos distintos e, consequentemente, operarem transformações simbólicas e reinvenções de linguagens (ver Velho, 200I, 2006; Heinich, 2008). Uma das mediações empreendidas pela arte é o direcionamento do olhar. A forma de "enquadrar" o mundo é sugerida pela pintura, pela literatura, pelo teatro, sem que os leitores, ou espectadores, sequer percebam. Pois, ao esquadrinhar cenas, ao engendrar e recortar situações, em busca do envolvimento do público, o artista através de sua arte, estabelece, ainda que inconscientemente, certa "pedagogia do olhar".

"A maneira de olhar é, no homem, em parte inata, em maior parte aprendida dos outros", conforme sublinhou Berthold Ölze (I998: 222). A seu ver, mesmo o passeio, atividade de lazer comum no final de semana, é uma "instituição cultural", por ser fruto de um aprendizado já internalizado: sabe-se como e para onde olhar. Os passeios são imagens recorrentes na literatura do final do século XVIII e no século XIX e, dependendo do roteiro e do ambiente escolhido, podem servir de estímulo à reflexão interior ou às conversas mais intimistas e intelectualizadas, quando a natureza lhe serve de cenário, ou a encontros de socialização, quando a paisagem urbana ganha destaque. Seja elevado à categoria de arte para os espíritos cultivados, conforme a concepção do filósofo alemão Karl Schelle no tratado A arte de passear (2001[1802]), 
ou tomado como um divertimento, a imagem do passeio é uma "instituição cultural" por configurar um "modo de ver" ${ }^{\mathrm{I}}$, de movimentar o corpo e pressupor um percurso.

Neste ensaio, ${ }^{2}$ usarei a ideia do passeio como fio condutor de um estilo específico das artes cênicas: o "teatro ligeiro musicado"3 escrito por Arthur Azevedo (I 855-I908).4 Frequentadas por um público amplo e heterogêneo, que incluía desde as classes populares até membros da elite, não necessariamente intelectualizada, tais peças sugeriam aos espectadores um passeio pela cidade através dos seus quadros. É tomando a visão como um "instrumento de conhecimento" (Aumont, 2004), que procurarei estabelecer o "enquadramento" do olhar, apresentado por Arthur Azevedo na revista de ano O Tribofe (I892) ao encenar, logo na abertura da peça, certa pintura da paisagem urbana do Rio de Janeiro, o panorama de Victor Meirelles e Lagerock. ${ }^{5}$

O foco da reflexão se dará na intercessão do gênero revista de ano com a pintura de um panorama urbano exibido na própria cidade, que lhe serviu de modelo. De que modo o uso do panorama do Rio de Janeiro pela peça O Tribofe colocava em cena a percepção da vida moderna plasmada a partir da experiência urbana? ${ }^{6} \mathrm{~A}$ vida nas metrópoles afetou seus habitantes tanto em relação à organização de seus padrões mentais ao ritmo acelerado das interações, às relações impessoais mediadas pela previsibilidade monetária e à preponderância do cálculo racional, conforme mostrou Georg Simmel,7 como também fez emergir uma cultura de espetáculos de entretenimento popular, que aguçavam os sentidos, mas, ao mesmo tempo, se ancoravam na vida cotidiana ${ }^{8}$ - como o teatro de revista e os panoramas. Tais formas de divertimentos ajudaram esses públicos a construírem seus quadros cognitivos sobre a experiência urbana.

É importante, ainda, sublinhar que esse novo estatuto do olhar, encenado pelo teatro de revista e pelos panoramas, segundo Jonathan Crary (2012), é produto de uma construção histórica, que se radicaliza no início do século XIX, quando aparatos ópticos, saberes científicos e instituições se amalgamam e se reorganizam, rompendo o paradigma visual renascentista e propiciando o surgimento de um novo tipo de observador na Europa do final do século XIX e do século XX, "um observador subjetivo", totalmente distinto dos séculos anteriores. A reorganização do olhar desse sujeito observador ocorre antes do surgimento da fotografia e do cinematógrafo, por estar relacionada a um novo ordenamento do conhecimento, do discurso e das práticas sociais que viriam a modelar as formas da indústria do entretenimento visual e do espetáculo no século XX. Nas palavras de Crary:

não basta descrever uma relação dialética entre inovações dos artistas e escritores de vanguarda no final do século XIX, de um lado, e o "realismo" e o positivismo correntes da cultura científica e popular, de outro. Ao contrário, é fundamental ver os dois fenômenos como componentes superpostos de uma única superfície social, na qual a modernização da visão tinha começado décadas antes [...]. [O que 
interessa é] o modo como os conceitos da visão subjetiva e a produtividade do observador impregnaram não apenas os campos da arte e da literatura, penetrando também nos discursos filosóficos, científicos e tecnológicos. Em vez de enfatizar a separação entre arte e ciência no século XIX, o importante é ver como ambas se integravam em um único campo entrelaçado de saberes e práticas (20I2: I4 e I8).

Assim, o sujeito observador do final do século XIX, que será discutido no presente artigo, está circunscrito em um "sistema" de convenções, de constrangimentos, de discursos e de práticas sociais, tecnológicas e institucionais, que estão em contínua transformação, sendo "causa e consequência da modernidade" (Crary, 20I2: I8). Apesar das diferenças entre os contextos europeu e brasileiro - principalmente no que tange à produção industrial e suas relações de trabalho - é possível perceber, ainda no Império, a partir do Segundo Reinado, a disseminação de um "bando de ideias novas" nos repertórios científico, literário e filosófico, reconfiguradas, mas não copiadas, da Europa para a situação local (ver Alonso, 2000).

Assim, no Rio de Janeiro recém-republicano, se por um lado, modos de viver tradicionais se misturavam às aspirações e imagens da modernidade, por outro, os entretenimentos, sobretudo as revistas de ano, bastante populares na época, traduziam - assim como os panoramas na Europa, tão bem ilustrados por Benjamin em Paris, capital do século XIX (1985) e Passagens (2007) - uma fusão entre arte e técnica, que não apenas expressava um "novo sentimento de vida", mas cujo produto se oferece como imagens-mercadorias prontas para serem consumidas pelos olhares ávidos por novidades do consumidor-observador.

As revistas de ano constituíam um gênero do teatro ligeiro musicado e que, de forma satírica, apresentavam os principais acontecimentos do ano anterior, assemelhados à crônica jornalística, ${ }^{9}$ ou seja, estavam coladas ao cotidiano e envolviam a plateia pelo riso. Constituíam-se na maior produção de Arthur Azevedo ${ }^{\mathrm{IO}}$ e, nas palavras do comediógrafo, eram frequentadas por um "público" heterogêneo, composto de "pobres ou, quando muito, [de] remediados, isto é, os que [viviam] de um rendimento certo e tinham que sujeitar a

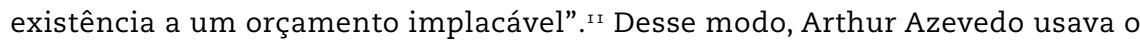
teatro, gênero preferido das camadas populares e camadas médias baixas, para delas se aproximar e conquistá-las. E para isso se valeu de recursos linguísticos como o uso da fala popular ${ }^{12}$ para construir seus personagens e da estética mais associada ao popular: a comicidade. Mas, ao mesmo tempo, seu humor não o isentava de um projeto pedagógico, projeto esse que, por se nutrir de elementos que representavam a complexidade da vida urbana, acabava por ser mais uma intenção do que uma realização. ${ }^{13}$ 


\section{PRIMEIRO ATO DE O TRIBOFE: O PANORAMA DO RIO DE JANEIRO}

Em I I de junho de I $892^{\mathrm{I} 4}$ estreava, no Teatro Apolo, na Capital Federal da recém-República, a revista de ano O Tribofe, de Arthur Azevedo, peça de teatro satírica que passava em revista os principais acontecimentos do ano anterior. A partir do olhar de uma família vinda do interior do Brasil ${ }^{15}$ e de passagem pelo Rio de Janeiro, o espectador rememorava o pretérito recente, o ano de I89I, tendo como cenário a cidade. Vários eventos que marcaram o ano anterior figuraram no decorrer dos quadros da peça: a crise econômico-política, que ficou conhecida como encilhamento, ${ }^{16}$ as doenças infectocontagiosas responsáveis pela alta mortalidade na capital, como a febre amarela e a varíola, os jornais de maior circulação e os que apareciam e faliam, os grandes espetáculos teatrais que deram "enchentes" (como eram denominadas as casas cheias no teatro), que se misturavam aos tipos urbanos como apostadores de cavalos, jóqueis, especuladores, cocotes e pessoas comuns, circulando por localizações específicas da cidade, como o hipódromo Derby Club, ${ }^{17}$ a Praça XV, o Passeio Público, a Rua do Ouvidor...

As revistas de ano e, sobretudo as escritas por Arthur Azevedo, por sua característica referencial aos últimos acontecimentos, sempre privilegiou a cidade do Rio de Janeiro como cenário e tema. ${ }^{18}$ Vale ressaltar a "capitalidade" do Rio de Janeiro ${ }^{19}$ que por ser, primeiro, capital do Império e, depois, da República, protagonizava os principais acontecimentos políticos, sociais e culturais que ocorriam e tornava-se o principal eixo das notícias a serem transmitidas para o resto do país. No entanto, em O Tribofe, mais do que nas outras revistas do autor, o Rio de Janeiro revelou-se, simultaneamente, como percurso, personagem e cenário. Logo na abertura da peça, a cidade é apresentada como um quadro que fornece o roteiro a ser aprendido, tanto pelo núcleo de personagens visitantes, como pelos habitantes da capital. Não são o compadre e a comadre, ${ }^{20}$ personagens que convencionalmente conduzem as revistas de ano, a apresentarem o enredo da peça. Aliás, o compadre Tribofe e a comadre Frivolina, só aparecem na $2^{\text {a }}$ cena do primeiro ato. Quem introduz O Tribofe aos espectadores é a pintura da cidade, precisamente o "Panorama do Rio de Janeiro", pintado por Victor Meirelles e o belga Henri Lagerock, a partir do Morro de Santo Antônio, e que fora exposto, no ano anterior (I89I), em uma construção circular específica (a rotunda), localizada na Praça XV de Novembro, ponto central de circulação na cidade. Assim, a pintura servia de moldura para o enredo, de cenário e de referência, por trazer a "great attraction" ${ }^{21}$ do público fluminense, no ano anterior.

Ao se abrirem as cortinas, aparece enquadrado no palco o interior da rotunda, quando da inauguração do panorama. ${ }^{22} \mathrm{Em}$ cena, os visitantes e o comendador Victor Meirelles. ${ }^{23} \mathrm{O}$ quadro pintado pela peça é de intenso movimento: alguns entram, outros saem, há quem aprecie a pintura circular, há quem escreva no álbum de visitantes suas impressões, há quem passe os olhos pelos folhetos explicativos sobre o panorama disponíveis no local. E o panorama é homenageado em canto e verso: 


$\begin{array}{ll}\text { Coro: } & \text { Oh! Que belo panorama! } \\ & \text { Que trabalho! Que primor! } \\ & \text { Ganhará dinheiro e fama } \\ & \text { O senhor comendador! } \\ \text { Comendador: } & \text { Venham ver uma obra-prima (...) } \\ & \text { Desde França, está provado } \\ & \text { Que defronte desta tela } \\ & \text { Fica tudo estatelado! } \\ & \text { Oh! Que belo panorama! }\end{array}$

Depois da cantoria, eis que se posiciona, no centro do palco, o núcleo fixo da peça: a família de fazendeiros, de São João do Sabará, interior de Minas Gerais, composta por seu Euzébio (o marido e chefe da família), por D. Fortunata (a mulher), Quinota (a filha), Juca (o filho mais novo) e Benvinda (cria da fazenda que viera junto com a família). Os personagens do interior imersos na paisagem urbana localizam e aprendem os bairros, acidentes geográficos e edifícios conhecidos a partir do painel e da interação com os moradores da cidade. Apropriam-se, assim, da cartografia urbana, da mesma forma que a rotunda se integrava ao espaço e oferecia uma visão pictórica aos habitantes da metrópole que por lá passavam.

Euzébio, à família - Óia a ia das Cobra! ${ }^{24}$

$\mathrm{I}^{\circ}$ visitante - Onde, senhor?

Euzébio, apontando - Ali.

$I^{\circ}$ visitante - Está enganado. Aquilo é a Fortaleza de Villegaignon.

Quinota, a Dona Fortunata - Olhe, mamãe, aquela rua é que era o quintal da freiras da Ajuda. [...]

Mas o que tal família do interior fazia no Rio de Janeiro? O contexto é cantado em coplas ${ }^{25}$ logo no início da cena, quando se apresentam ao espectador e ao idealizador do panorama. Vieram à Capital Federal em busca do Seu Gouveia, um janota, ${ }^{26}$ que quando passou pela fazenda de Seu Euzébio pediu a mão de Quinota e desapareceu, a pretexto de tratar dos papéis do casamento. ${ }^{27}$ A moça ficou desconsolada e seu Euzébio decidiu, então, passar uma temporada na Capital Federal, com a família, para resolver a situação. Mas, por quais razões tal família adentrou logo na rotunda da Praça XV? A Praça XV era o nome dado, a partir dos ventos republicanos, ao antigo Largo do Paço, famoso nos tempos da Colônia e do Império, cuja edificação principal, o palácio adminis trativo, abrigara inicialmente a Corte, quando de sua chegada ao Brasil. Era um lugar tradicional, situado na parte central da cidade, de fácil acesso, irrigado por transporte e com fluxo intenso de pedestres, que trazia uma novidade: uma grande estrutura metálica circular, a rotunda, que abrigava a pintura do panorama do Rio de Janeiro. E se tal arquitetura redonda atraía os habitantes da cidade, como não poderia despertar a curiosidade dos visitantes interioranos? Por suas grandes dimensões, ${ }^{28}$ por utilizar um jogo de sombra e luz e pela localização do espectador em uma plataforma no centro da rotunda, sugeria uma imersão, conferindo a ilusão de realidade de experimentar uma 
"paisagem real". Também era possível, como sugere Benjamin em Passagens (2007: 574), olhar a cidade "real" dentro da casa, pressupondo que "o que se encontrava na casa sem janelas [era] o verdadeiro", pois, tal experiência visual fornecia um mapa; no caso da peça, um mapa do Rio de Janeiro que reforçava a identificação de seus habitantes e familiarizava os visitantes que pouco ou nada conheciam da Capital Federal. Ótima sugestão de percurso para viajantes explorarem a cidade e também para os moradores perceberem a sua cidade sob nova perspectiva, aquela pintada pelo artista.

Mas, se o mapa fornecido pelo panorama era reconfortante, a cidade do Rio de Janeiro, com uma população acima de 500 mil habitantes, ${ }^{29}$ não se mostrava tão acolhedora para a família de fazendeiros. Logo de início, os visitantes enfrentaram grande dificuldade para se acomodar: hotéis cheios e pouca oferta de casas para alugar (preços abusivos que sobem continuamente, além da escassez de imóveis). Chegam a dormir em um bonde. Ao passarem pela Praça XV, encontram a rotunda, entram por curiosidade e acreditam que o espaço pode ser feito de pernoite, já que ficava aberto, apenas, durante o dia. No diálogo fictício entre a família e Victor Meirelles:

Euzébio - [...] Não temos casa, meu sinhô! [...] e era justamente por isso que eu desejava falá a vosseoria. [...] Magine que cheguemo onte e procuremos cômados em todos os hoté. Nem um quarto desocupado! Quisemos alugá casa. Quá casa, seu compadre! [...] Passemos a noite dentro de um bonde na Rua do Riachulelo, c'as cortina arriada. Cada um de nós tomou conta de um banco.

$[\ldots]$

Comendador - Mas, afinal que desejam de mim?

Euzébio - Eu le digo. Nós passemo inda agorinha por aqui e vimo este barracão. ${ }^{30}$ Comendador - Diga "pavilhão".

Euzébio - Ué! Pavilhão não é bandeira?

Comendador - Se não quiser dizer pavilhão, diga "rotunda".

Euzébio - Pois bem, passemo por esta rotunda e perguntemo o que era. Nos disserum que era o panorama do Ri' de Janeiro, e que só estava aberto de dia. Então me alembrei de vi falá a vosseoria pra me alugá durante a noite [...].

[....]

Comendador - O senhor está doido! Aqui não há espaço!...[...] nem ar! O senhor não vê como faz calor aqui? [...] Se querem continuar a conversar, vamos lá para baixo. Aqui já está muito escuro!

$[\ldots]$

Euzébio - Ora! Estava tão bão este cômado! Deste lado ficava eu e Dona Fortunata. Dona Fortunata - Não; se eu ficasse era ali do lado da barra, que deve ser mais fresco. Euzébio - Tá bão... A gente não havia de brigá... Aqui do lado da Tijuca ficava Quinota e Benvinda... E Juca ficava ali... [...]

A passagem acima mostra como a família interiorana ia se apropriando da pintura, e da cartografia urbana, ao mesmo tempo em que a arquitetura da rotunda se integrava ao espaço urbano e oferecia uma visão pictórica aos habitantes da metrópole que por lá passavam. Para os moradores do Rio de Janeiro, era como participar de uma viagem na própria cidade, vivenciar uma experi- 
ência que aguçava todos os sentidos, embora privilegiasse a visão. O mesmo se dava com os espetáculos do teatro ligeiro musicado, que incluíam números de canto e dança, e provocavam o riso por referirem-se ironicamente aos acontecimentos pretéritos, envolvendo o espectador como parte integrante da obra.

Pintura de paisagem, cidade, panorama e teatro se misturavam em um espetáculo, no qual a arte servia ao entretenimento. O panorama, diga-se de passagem, foi um dos mecanismos de difusão pioneiros do divertimento para as massas, tendo as paisagens e as cidades como temas de destaque (Coelho, 2007: I6; Benjamim, 2007: 569-584). É importante ressaltar que tecnicamente o panorama está inscrito no gênero pintura que, por sinal, pressupõe um intenso trabalho de vários artistas para reproduzir os efeitos de sombra e luz, necessários à ilusão de realidade, e não raro usava a emergente técnica da fotografia como auxiliar neste empreendimento. ${ }^{31}$ As paisagens eram temas recorrentes nos panoramas e, no caso do "Panorama do Rio de Janeiro", a paisagem urbana se destacou. Vista do alto dos morros e fixada na tela pelos artistas, os casarios eram representados no centro da tela, tendo no fundo a baía de Guanabara. Tendência, aliás, comum às paisagens de vistas das cidades da segunda metade do século XIX, a experiência moderna mudara o eixo do rural para o urbano, assim as telas ressaltavam a dimensão urbana, reduzindo o espaço destinado à natureza (Chiavari, 2000; Lira, 2000).

Mas não apenas a visualidade da paisagem urbana é construída e sugere um mundo a ser visto de certo modo (Lira, 2000); a própria concepção de paisagem, como a reconhecemos, é historicamente localizada. ${ }^{32}$ Como sublinha Alain Roger, a paisagem não é "uma realidade natural, mas sempre uma criação cultural, que surge nas artes antes de se configurar diante de nossos olhos". ${ }^{33}$ Trata-se de um recorte do espaço, enquadrado na "janela pictórica" (ver Roger, 2000: 35). Ou seja, os elementos visíveis não conformam uma paisagem, ela é uma operação do artista que ao retirar elementos da natureza, os combina em uma forma, cuja matriz identificamos como "paisagem". ${ }^{34}$

\section{A PEDAGOGIA DO OLHAR}

Mas qual seria a diferença da pintura de paisagem, de uma vista panorâmica, em uma tela e a paisagem pintada em imensos painéis e disposta em forma circular, denominada panorama? O panorama ${ }^{35}$ - neologismo formado pela junção de dois termos gregos pan (todo) e horama (visão) - requer um dispositivo, uma arquitetura própria, circular e que possua uma plataforma em que o espectador possa apreciar a totalidade da obra a partir de um ponto fixo. Nasce assim como um espetáculo e antecipa o cinema, sem o seu movimento. "Fabricado como pintura, o panorama é destinado a ser visto como cinema" (Aumont, 2004: 55), , ${ }^{66}$ reconhecendo o espectador como coautor e como partícipe da experiência de ilusionismo. ${ }^{37}$ Posicionado no centro da rotunda, o espectador era envolvido 
pela imagem, sem perceber os artifícios da simulação (Grau, 2007; Pesavento, 2008; Coelho, 2009; França, 20I I). Bastante popular na Europa, a partir do final do século XVIII, o sucesso dessa forma de entretenimento se encontra amalgamado à percepção estética do horizonte, cujas raízes partem de alguns dos pressupostos iluministas, como a sedução pelo controle do mundo circundante: da natureza, do tempo, do espaço e dos outros. O mundo é transformado em paisagem a qual o sujeito tem o desejo de observar de modo onipresente e onisciente (Pesavento, 2008). O olhar deixa de ser "ponte" para o mundo (Rouanet, I988) e passa a ser uma forma de poder, de controle, de construção de saber e de poder, como nos fala Foucault (2002 e 2003). O "panóptico", como indica Benjamin, é o local onde tudo se vê e de todas as maneiras. É onde o universalismo do século XIX se monumentaliza e se manifesta como "uma obra de arte total" (2007: 573), pois, as artes e até as formas de entretenimento vão direcionar a visão para o que merece ser percebido e admirado, exercendo papel fundamental nessa "pedagogia do olhar".

E qual seria a relação entre teatro e panorama? O panorama "teatralizava" a paisagem urbana e compartilhava com o teatro ligeiro musicado a característica de entretenimento popular, fruto da emergente cultura de massa que se expandia no século XIX e feito para atrair o espectador pagante, o sustentáculo dessa indústria da diversão. ${ }^{88}$ Teatro ligeiro e panorama não eram apreciados artisticamente, por sua aura, por seu valor de culto, usando a expressão de Benjamin (20I0[1936]), mas pela sua capacidade de provocar sensações e seu efeito de realidade. Conforme Vanessa Schwartz (2004), o gosto do público pela realidade e pelos assuntos do cotidiano no último quartil oitocentista se coadunou com o interesse por outros gêneros como a imprensa sensacionalista e os museus de cera, ambos vistos como entretenimentos envolventes. Embora a autora não fale do teatro ligeiro musicado, podemos incluí-lo no mesmo rol, pois sua capacidade de atração se dá por motivos afins.

No entanto, mesmo no lazer havia uma intenção pedagógica. Ao menos em certo tipo de lazer como as revistas de ano de Arthur Azevedo e o panorama de Victor Meirelles. Primeiro, o espaço mais comum de exibição do panorama, as Exposições Universais, já emprestava certa pedagogia civilizacional. Muito em voga na Europa, e posteriormente nos EUA, as Exposições Universais pretendiam, entre outras coisas, promover uma ocupação no tempo livre com fins pedagógicos, divulgar códigos de etiqueta adequados à vida moderna e burguesa e direcionar o olhar para o que merecia ser visto e admirado. ${ }^{39}$ Como a própria leitura da peça de Arthur Azevedo indica, Victor Meirelles não apenas criava uma paisagem da cidade a partir de seu panorama, mas através do recurso de folhetos explicativos, disponíveis na rotunda, pretendia assegurar-se da compreensão do espectador não apenas sobre a técnica da pintura circular, como também transmitir informações geográficas e históricas sobre a cidade. Se em um primeiro momento, Victor Meirelles, então parceiro de Henri Lange- 
rock, pretendia mostrar o "Panorama do Rio de Janeiro" para os europeus, ${ }^{40}$ ao término da sociedade com o pintor belga o artista brasileiro voltou sua atenção para a terra natal, ambicionando ser admirado pelo seu pioneirismo ao trazer o panorama circular para a Capital Federal. A paisagem urbana do Rio de Janeiro seria exibida como um espetáculo para os próprios habitantes que - conforme os folhetos explicativos de Meirelles - do alto da plataforma, no epicentro da rotunda, teriam "a mais completa ilusão", confundindo o que é natural com o artificial e surpreendendo-se com "uma vista que talvez nunca imaginasse[m] e nem mesmo poderia[m] gozar sem o auxílio da arte"..$^{4}$

Contemporaneamente, é difícil imaginar os panoramas oitocentistas, pois eles desapareceram logo início do século XX, ultrapassados pelos moving panorama (Coelho, 2007). Quanto ao "Panorama do Rio de Janeiro" de Victor Meirelles, pouco restou. O imenso painel se deteriorou, só sobraram seis estudos que lhe serviram de subsídio e estão guardados no acervo do Museu Nacional de Belas Artes: ${ }^{42}$ Largo do Rocio, Vista sobre a Candelária, Ilhas das Cobras, Morro do Castelo, Entrada da Barra do Rio de Janeiro e Morro do Corcovado e Tijuca. Juntas, estas telas, como podemos ver - nas imagens das figuras I, 2, 3 e 4 - dão uma ideia do que teria sido de fato o panorama.

E quanto à concepção de lazer, com laivos civilizatórios, de Arthur Azevedo? Em suas revistas de ano, o autor desejava divertir e manter a indústria do teatro, 43 sem, no entanto, abrir mão de uma literatura engajada com os preceitos educacionais da elites letradas. Um projeto que se propunha a lapidar as sensibilidades das massas, pressupondo que as camadas populares não apenas fossem portadoras do mesmo "mecanismo de verdade" interna, pelo uso da razão, empreendido pelos intelectuais herdeiros das luzes, como tomando como base a ideia de aperfeiçoamento humano, de "perfectibilidade" 44 como meta. Assim, procurava inserir valores burgueses, modernos, usando o humor como instrumento pedagógico.

\section{CAI O PANO...}

A inserção de uma pintura como ponto de partida para a apreensão do código urbano por uma família vinda do interior na revista de ano O Tribofe, não apenas favorece o intercâmbio dos gêneros "artes plásticas" e "teatro", mas sugere que a cidade possa ser ao mesmo tempo encenada e lida como um quadro. 45 A visualidade passa a ser, assim, a base do teatro de revista, como também a capacidade de transformar o espectador em partícipe da experiência, através da sensação de descolamento, seja geográfico ou no tempo. É um passeio pela cidade e pelos escaninhos da memória recente, realizado com o espectador parado, mas que se movimenta com a imaginação, a partir do olhar. E o mundo exterior parece caber na janela pictórica do palco, no espaço que se encontra visível ao olho do espectador. Mas, apesar de estar delimitado pelo enquadramento do palco, esse sujeito que olha, em sua poltrona, tem a impressão de 
tudo controlar e conhecer. Seu olho se emancipa da função de órgão e passa a ser vivenciado como a medida de todas as coisas. Afinal, usando as palavras de Merleau-Ponty, “Tudo o que vejo por princípio está ao meu alcance e ao alcance do meu olhar, assinalado no mapa do 'eu posso'. Cada um dos dois mapas é completo. O mundo do visível e o mundo dos meus projetos motores são partes totais do mesmo ser" (I975: 278).

Recebido em 06/02/2013 | Aprovado em Io/og/2013

Tatiana Siciliano é doutora em Antropologia Social pelo Museu Nacional/UfRJ e professora da Pontifícia Universidade Católica do Rio de Janeiro (PUC-Rio). É pós-doutora pelo Instituto de Filosofia e Ciências Sociais da Universidade Federal do Rio de Janeiro (IFCS-UFRJ/Capes) e atua nas áreas de antropologia urbana, sociologia da arte e televisão e consumo. É autora de "Metamorfoses guanabarinas: O Rio de Janeiro no raiar do século XX por Arthur Azevedo" (2013) e de "Uma questão de gênero. Os contos ligeiros de Arthur Azevedo" (2012). 


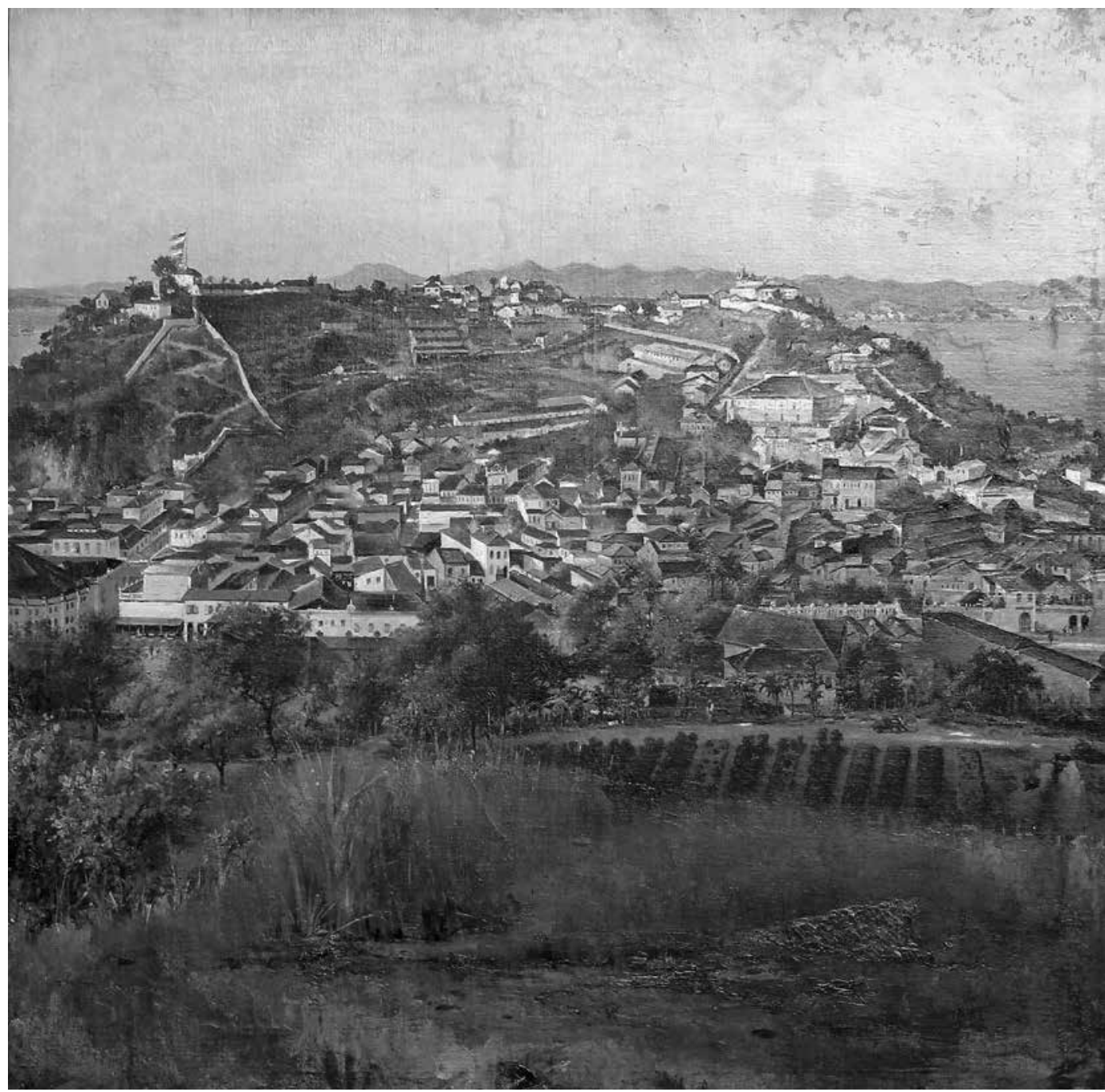

I

Figura I

Estudo para o "Panorama do Rio de Janeiro" (Morro da Conceição e Igreja da Candelária), óleo sobre tela, circa I885. Acervo do Museu Nacional de Belas Artes do Rio de Janeiro. Foto de Claudio Baptista. 


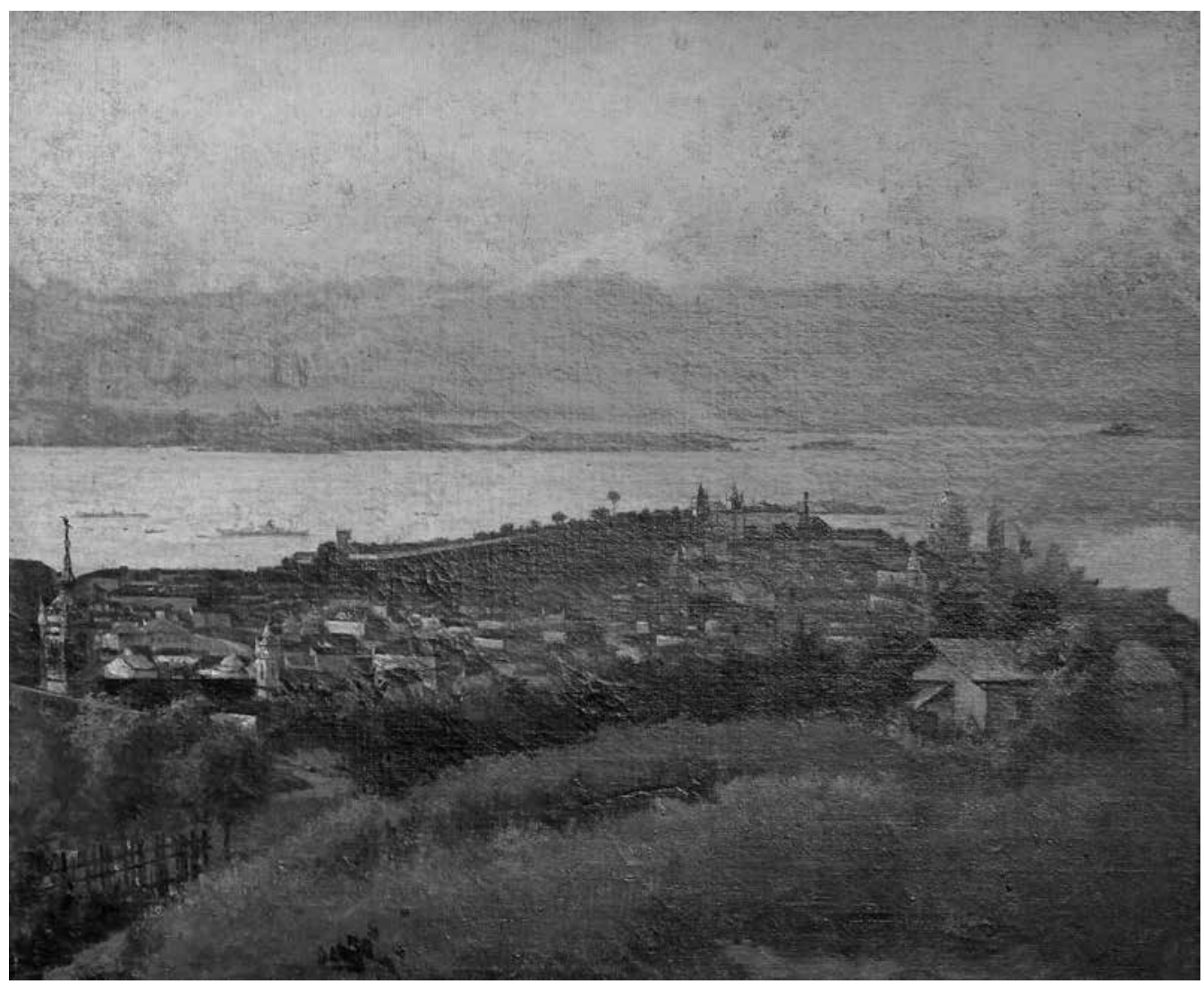

2

Estudo para o "Panorama do Rio de Janeiro" (Morro do Castelo), óleo sobre tela, circa I885. Acervo do Museu Nacional de Belas Artes do Rio de Janeiro. Foto de Claudio Baptista. 


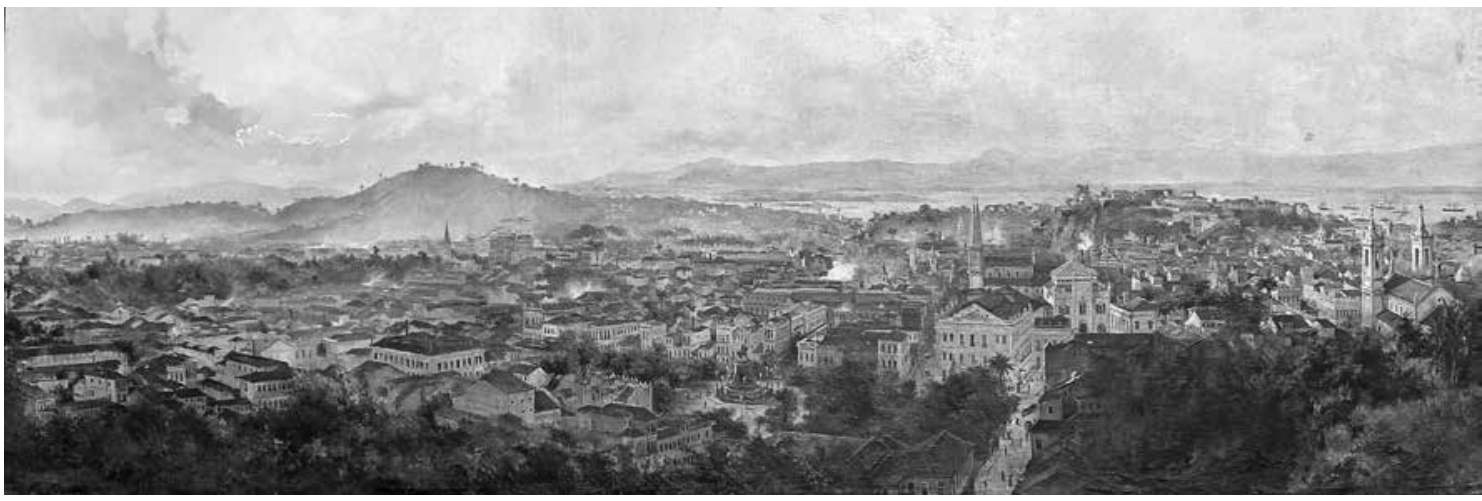

3

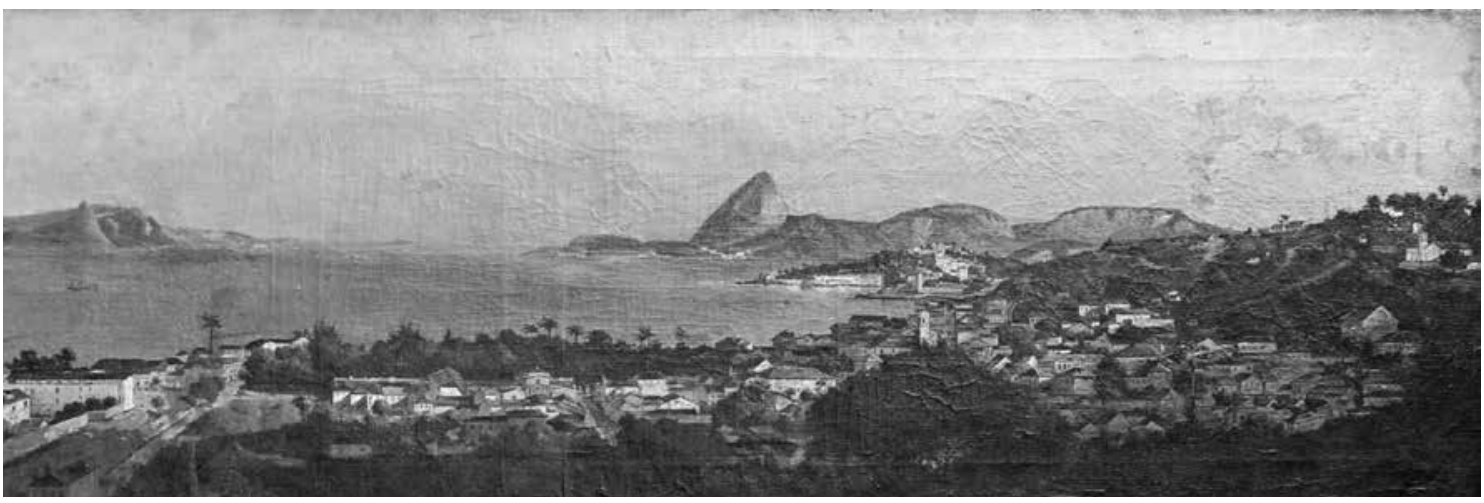

4

Figura 3

Estudo para o "Panorama do Rio de Janeiro" (Morro de Santo Antônio e Largo do Rocio), óleo sobre tela, circa I885. Acervo do Museu Nacional de Belas Artes do Rio de Janeiro. Foto de Claudio Baptista.
Figura 4

Estudo para o "Panorama do Rio de Janeiro" (entrada da Barra), óleo sobre tela, circa I885. Acervo do Museu Nacional de Belas Artes do Rio de Janeiro. Foto de Claudio Baptista. 


\section{NOTAS}

I Conforme Berger, "Só vemos aquilo que olhamos. Olhar é um ato de escolha" (I999:Io).

2 O ensaio, aqui entendido como um estilo que permite a experimentação, a criatividade ao narrar, abriga a multiplicidade de horizontes. É uma forma literária que sugere o passeio, a mobilidade, a maleabilidade, a aventura. Sobre o estilo ensaístico, ver Waizbort (2000: 35-74).

3 Pode-se definir o teatro ligeiro musicado como espetáculos cômicos e alegres, oriundos da Europa, que incluíam números de canto e dança, efeitos cênicos e cenas dramáticas. Ver Prado (2008), Marzano (2010), Mencarelli (I999), Faria (200I) e Pavis (2008).

4 Embora pouco lembrado contemporaneamente, Arthur Azevedo foi bastante conhecido no campo artístico-intelectual de seu tempo, exercendo múltiplos papéis: contista, cronista e funcionário público. Lutou pela construção do Teatro Municipal, pela consolidação do teatro nacional e foi membro fundador da Academia Brasileira de Letras (I897).

5 "O panorama do Rio de Janeiro" foi pintado a partir de parceria firmada, em I885, entre Mereilles e o pintor de paisagem, o belga Henri Langerock. O projeto foi concebido para ser uma atração para um grande público, como estava em voga na Europa e pretendia-se exibi-lo nas principais capitais europeias e, depois, nas duas Américas. A pintura foi exposta, no entanto, apenas em Bruxelas (I988) e Paris (1889). Depois disso, veio para o Brasil, em I89 I, com a sociedade entre Meirelles e Langerock já desfeita. A ideia do panorama sobre o Rio de Janeiro não era nova. Um panorama circular da cidade já fora anteriormente exposto em Paris, em I824, executado por Prévost e pintado por Frederic Rommy, a partir de desenhos de Félix Taunay. Mas, no Brasil, era a primeira vez que uma pintura desse gênero era exposta.

6 A modernidade aqui entendida como um constructo que enfatiza as mudanças subjetivas dos habitantes em relação às rápidas transformações ocorridas nas dimensões econômico-sociais (prevalência do modo de produção capitalista, crescimento das cidades e inovações científico-tecnológica e emergência de uma cultura de massa) e na visão de mun- 
do, que passa a ser enxergado pela lente racionalista. Ver Charney \& Schwartz (2004) e Singer (2004).

7 Ver Simmel, em As grandes cidades e a vida do espírito (2005[1903]), as grandes cidades, como a Berlim de seu tempo, criaram as condições psicológicas e neurológicas, "os fundamentos sensíveis da vida anímica", de seus habitantes, o Homo Urbanus.

8 Sobre a discussão do gosto do público, ao experimentar a vida moderna do século XIX, por gêneros de entretenimento que enfatizassem o cotidiano e despertassem sensações, ver Singer (2004) e Cohen (2004).

9 Sobre a revista de ano no Brasil, ver Ruiz (I 988), Veneziano (I99I; I996) e Paiva (I99I). Sobre as relações entre acontecimentos no Brasil e as revistas de ano de Arthur Azevedo, ver Süssekind (I986), Mencarelli (I999), Prado (I986; 2008), Faria (200I), Veneziano (I99I) e Brandão (2008).

Io Arthur Azevedo escreveu I9 revistas de ano, e, mesmo sem ser o precursor do gênero no Brasil, foi o primeiro a popularizá-lo.

I I Ver "O Theatro", em A Notícia, 24/or/I905. Se empreendermos uma pesquisa mais aprofundada nas páginas sobre teatro dos jornais do final do século XIX, como foi realizado por Carvalho (2009) e Mencarelli (I999), veremos que os espetáculos ligeiros eram frequentados por todas as classes econômicas, inclusive pelas elites.

I 2 Ao usar as falas das camadas populares como forma de aproximação, Arthur Azevedo incorporou à sua obra elementos da cultura popular, marginalizados pelos escritores da época e só apropriados muito tempo depois, em outro sentido, pelo modernismo. Ver Martins (I988) e Neves (2008).

I3 Mesmo que as revistas de ano se propusessem a inventar um Rio de Janeiro, como sublinhou Flora Süssekind (I986), a apropriação dessa mensagem por seus receptores nem sempre estava em conformidade ao "enquadramento" pretendido pelos autores, como mostrou Mencarelli (I999), a partir do estudo sobre a recepção da revista de ano $O$ bilontra. O foco desse estudo residirá sobre o material escrito, não a apreensão do mesmo pelos espectadores, enfatizará a intenção pedagógica e não a polifonia provocada pela 
obra. Sobre o efeito polifônico na obra de Arthur Azevedo, ver Mencarelli (I999) e Siciliano (20 I I). Sobre a questão da resignificação das obras literárias, ver Chartier (I99I; 200I).

I4 Ver anúncio e notinha no jornal O Paiz, de I6/6/I892.

I5 A revista de ano O Tribofe, décima revista de ano de Arthur Azevedo, inspira a burleta A Capital Federal (I897), considerada, pela crítica teatral como a obra-prima do autor. Essa burleta (comédia-opereta de costumes nacionais) perde sua característica referencial, os fatos do ano anterior não mais são elementos do enredo, e ganha densidade no núcleo de personagens, que conta com novos papéis e cenas ampliadas.

I6 Reforma bancária, empreendida pelo então ministro da Fazenda Rui Barbosa, que promoveu oferta de dinheiro e facilitou a abertura de sociedades anônimas, resultando em especulação financeira.

I7 O Derby ficava onde hoje está o estádio de futebol Maracanã, no Rio de Janeiro.

I8 Partilho da análise de Süssekind (I986) de que a sedução da metrópole-capital estava alinhada com o fortalecimento do gênero teatral, revista de ano.

I9 Sobre essa questão ver Neves (I99I) e Pereira (2010).

20 O compadre e a comadre, traduções do francês compère e commère, são fios condutores da revista de ano, aglutinam e dão sentido aos diversos quadros de variedades que compõem a revista e emprestam coerência ao enredo. Ver Veneziano (I99I).

2 I Ver coluna "Sete Dias", publicada no jornal O Paiz, de I I/I/I89I, e assinada por JR (iniciais do jornalista João Batista Ribeiro de Andrade Fernandes). O panorama circular, embora fosse um espetáculo recorrente na Europa por cerca de Ioo anos, era a great attraction do público fluminense por ser uma novidade no Rio de Janeiro.

22 A exposição de um imenso panorama circular da cidade do Rio de Janeiro, pintado por Victor Meirelles e Henri Lagerock, era anunciada em O Paiz, de 3/I/I89I, na coluna "Artes e artistas". Os jornais da cidade glosavam diariamente o número de visitantes ao panorama. O empreendimento foi bem-sucedido: cerca de 70 mil pessoas o visi- 
taram, somando a frequência diária publicada no Jornal do Commercio. Ver, também, Considera (2000: 292) e Coelho (2007).

23 Referência ao título honorífico do pintor Victor Meirelles (1832-I903) - que fora aluno e professor da Academia Imperial de Belas Artes (I862-I890) - por ter recebido duas comendas do Imperador: Ordem do Rosa (em I872) e Ordem do Cristo (em I 872). Mereilles ficou conhecido, principalmente, pelas telas Primeira Missa no Brasil (I860) e a Batalha dos Guararapes (1879); ambas se encontram no Museu Nacional de Belas Artes, no Rio de Janeiro.

24 Como já foi dito, Arthur Azevedo costumava ressaltar a fala dos tipos caracterizados. Em O Tribofe, é marcado o lugar da família, o sotaque da roça e as lacunas da educação formal usuais entre os que viviam na área rural e não tinham o hábito de visitar as grandes cidades. Quinota, no entanto, por ser de outra geração, recebera instrução formal através de professores particulares. A retórica da filha mais velha - de Euzébio e Fortunata - era correta e próxima aos moradores instruídos do Rio de Janeiro. O que a identificava era o sotaque, não os erros de português.

25 Composição poética, em quadras, para ser cantada.

26 Homem que se veste com luxo.

27 Apesar de o Rio e Janeiro - Capital Federal da República

- ser encenado no palco, ele é representado de forma ambígua: é uma cidade, ao mesmo tempo, desejada e temida. O Rio era sedutor, com suas múltiplas diversões, mas também traiçoeiro, assim como os seus habitantes típicos. Seu Gouveia era um bom rapaz, mas ao retornar à Capital, em vez de tratar dos papéis para se casar com Quinota, es pecula financeiramente na Bolsa e envolve-se com uma cocotte. Era a cidade armadilha, na qual todos poderiam tornar-se presas fáceis: até o chefe da família e a mulata Benvinda caem em tentação, embora se arrependam no final da peça. Era difícil resistir ao tal "micróbio da pândega". Pois, como observou Quinota, havia "muita liberdade e pouco escrúpulo". O enredo abriga um duplo sentido: de um lado, diverte com a comicidade das situações e confere simpatia aos tipos urbanos; de outro, tem uma intenção moralizadora, que alerta para os perigos e as tentações da 
vida urbana. Essa passagem também chama a atenção para a observação das cidades grandes, por um olhar de "fora", de um habitante da cidade pequena, que percebe mais as contradições da cultura local do que os próprios moradores, que já a naturalizaram.

28 O painel media I I5 metros de comprimento e I4,5 de altura.

29 Ver o recenseamento de I890 - o Distrito Federal, somando as freguesias urbanas e suburbanas, possuía 522.56 I habitantes - em Damazio (1996).

30 Barracão era como os populares costumam a se referir à rotunda. Ver anedota sobre o panorama em O Paiz, I7/I/I89I.

3I A pintura de "O panorama do Rio de Janeiro" foi composta em partes e auxiliada a partir de estudos a óleo e de fotografias e levou I4 meses para ser pintado. Ver Considera (2000), Coelho (2007; 2009) e Peixoto (I988).

32 Ver Dominique Allart (2000). O pintor flamengo Joachim Patinier (I475-I524) é considerado um dos precursores da pintura identificada como paisagem e o primeiro a receber a designação de paisagista por criar um tipo particular de imagem que reúne elementos, tais como terra cultivada, florestas, montanhas, mar. Sobre o nascimento da "paisagem ocidental" ver, também, Roger (2000).

33 Ver Alain Roger (2000: 37), tradução minha do francês "paysage n'est jamais une realité naturelle, mais toujours une création culturelle, et qu'il naît dans les arts avant de féconder nos regards".

34 Sobre essa questão ver A filosofia da paisagem, de Georg Simmel (2009[1913]).

35 Técnica da pintura ilusionista patenteada por Robert Barker no final do século XVIII (I797). O panorama proporcionava uma sensação de imersão no espectador, que posicionado em uma plataforma, no ponto central e mais elevado da rotunda, como um mirante, tinha uma visão em 360 graus, bem distinta da apreciação de uma pintura em um quadro tradicional, por não ter moldura, e conferir uma forte sensação de realidade. Ver Grau (2007) e Coelho (2007; 2008).

36 Ver Aumont (2000) e Schwartz (2006). Até o início do século $\mathrm{XX}$ o panorama convive lado a lado com o cinematógrafo nas exposições e feiras, não concorrendo imediatamente com essa forma de entretenimento. 
37 Ver Grau (2007). A ideia de representação do real, que provocou a técnica do panorama, não foi concebida por Robert Backer. Ela é um desdobramento da busca das artes visuais pela virtualidade e pela imersão, que remonta ao mundo clássico e se aperfeiçoa, depois, com a fotografia e o cinema, e está presente, inclusive, na contemporaneidade através das mídias digitais e das tecnologias tridimensionais.

38 Sobre a emergência do teatro como cultura de massa, ver Charle (2010).

39 Sobre exposições universais, ver Neves (I986), Pereira (2010) e Levy (2008).

40 Victor Meirelles desejava, sobretudo, mostrar o grau de desenvolvimento urbanístico do Rio de Janeiro, visando atrair a mão de obra imigrante para o Brasil, além de tentar desfazer, aos olhos dos europeus, a imagem de um país selvagem, onde se poderia ser atacado, em plena urbe, por feras ou canibais. Daí valorizar o aspecto civilizacional da cidade, destacando o conjunto de prédios e conferindo à natureza (outrora em destaque) o papel de moldura. Ver Coelho (2007).

4I Ver texto do próprio pintor, "O panorama da baía e cidade do Rio de Janeiro: tomado do Morro de Santo Antônio no ano de i 886 por Victor Meirelles. Notícia explicativa." Retirado de Coelho (2007: I26).

42 Victor Meirelles doou em vida, em I902, todos os seus panoramas ao Estado, que não o conservou devidamente. Além do panorama do Rio de Janeiro, pintou outros dois, o da Entrada da Esquadra legal do porto do Rio de Janeiro (I896) e o do Descobrimento do Brasil (I90o), que, contudo, não foram bem-sucedidos. O pintor catarinense morre, em I 903, falido, por ter feito muitas despesas com o empreendimento dos panoramas e sem contar com os proventos de seu cargo de professor da Academia de Belas Artes, pois fora jubilado em I 890, com o advento da República, devido às suas ligações com o Império e disputas com os novos diretores. Ver Considera (2000) e Peixoto (I982).

43 Para Arthur Azevedo, se não fossem pelas peças do teatro ligeiro musicado, o teatro nacional acabaria sucumbido pelas operetas francesas. A solução seria fortalecer a in- 
dústria de entretenimento brasileira e, em paralelo, lutar pela criação de um espaço de desenvolvimento da arte dramática, sem fins lucrativos, e por isso patrocinado pelo Estado, a exemplo da Comédie-Française. Sobre essa questão, ver Siciliano (20I I).

44 Sobre a discussão das sensibilidades construídas no Ocidente nos séculos XVII e XVIII, Luis Fernando Dias Duarte (2000) desenvolve o conceito de "dispositivo de sensibilidade", que é análogo ao "dispositivo de sexualidade", cunhado por Foucault. Neste modelo se articulam três aspectos: a perfectibilidade, a experiência e o fisicalismo.

45 Na tradição literária, há inúmeros exemplos que enfatizam o intercâmbio de gêneros. Charles Baudelaire, em "O pintor da vida moderna" (I869), compara o conto de Edgar Alan Poe, "O homem da multidão" aos quadros de Constantine Guys, definindo o texto de Poe como "um quadro de verdade", por este captar, assim como as pinturas de G. (C. Guys), a poesia do efêmero presente na multidão. Anterior a Poe e Baudelaire, Ernest Hoffmann escreveu "A janela de esquina de meu primo" (I822), cuja leitura assemelha-se a um quadro, devido ao seu estilo visual e sensorial. No conto, um escritor inválido inicia seu primo, que lhe visitava, nas primícias da arte de enxergar e, a partir do diálogo, é possível imaginar a cena relatada - a buliçosa feira na praça central de Berlim, que se desenrola debaixo da janela de esquina do primo acamado.

\section{REFERÊNCIAS BIBLIOGRÁFICAS}

Alonso, Angela. (2002). Ideias em movimento. A geração de I 870 na crise do Brasil-Imperio. São Paulo: Paz e Terra.

Allart, Dominique. (2000). Contemplatio mundi. Le paysage cosmique à la Renaissance. In: Salgueiro, Heliana Angoti (org.). Paisagem e arte. A invenção da natureza. A evolução do olhar. São Paulo: CBHA/CNPq/FAPESP. (Trabalhos publicados no I Colóquio Internacional de História da Arte - CBHA/ CIHA), p. 65-72.

Araújo, Antonio Martins. (I988). Arthur Azevedo: A palaura e o riso. Uma introdução aos processos linguísticos de comicidade no teatro de Arthur Azevedo. São Paulo/Rio de Janeiro: Perspectiva/Ed. UFRJ. 
Aumont, Jacques. (2004). O olho interminável. Cinema e pintura. São Paulo: Cosac Naify.

Azevedo, Arthur. (I 986). O Tribofe. Rio de Janeiro: Nova Fronteira/Fundação Casa de Rui Barbosa (Organização de Rachel Valença).

Baudelaire, Charles. (I997). O pintor da vida moderna (I869). In: Sobre a modernidade. São Paulo: Paz e Terra.

Bauer, Leticia. (2009). Cronologia. In: Turazzi, Maria Inez (org.). Victor Meirelles. Novas leituras. Florianópolis/ São Paulo: Museu Victor Meirelles/Ibran/Minc, Studio Nobel, p. I63-I75. Benjamin, Walter. (I985). Paris, capital do século XIX. In: Sociologia. (Organização de Flávio R. Kothe). São Paulo: Ática, p. 30-43.

Benjamin, Walter. (2010 [1936]). A obra de arte na época de sua reprodutibilidade. In: Lima, Luiz Costa (org.). Teoria da cultura de massa. São Paulo: Paz e Terra, p. 22 I-254.

Benjamin, Walter. (2007). Passagens. Belo Horizonte/São Paulo: Ed. UFMG/Imprensa Oficial do Estado de São Paulo.

Berger, John. (1999). Modos de ver. Rio de Janeiro: Rocco.

Brandão, Tânia. (2008). Pum! Ou as surpresas do Sr. Artur Azevedo para o palco do século. In: Levin, Orna \& Neves, Larissa (orgs.). Teatro, literatura e imprensa na virada do século. Homenagem a Artur Azevedo. Remate de Males, 28/I, p. 9-20.

Carvalho, Danielle Crepaldi. (2009) "Arte" em tempo de "chirinola": A proposta de renovação teatral de Coelho Netto (I 897I898). Dissertação de mestrado. Programa de Teoria e História Literária/Universidade Estadual de Campinas.

Charle, Christophe. (20I2). A gênese da sociedade do espetáculo. Teatro em Paris, Londres e Viena. São Paulo: Companhia das Letras.

Charney, Leo \& Schwartz, Vanessa R. (orgs.). (2004). Introdução. In: O cinema e a invenção da vida moderna. São Paulo: Cosac Naify, p. I7-29.

Chartier, Roger. (I99I). O mundo como representação. Estudos Avançados, II/5, p. I73-I9I.

Chartier, Roger. (200I). Cultura escrita, literatura e história: Conversas de Roger Chartier com Carlos Aguirre Anaya, Jesús Anaya Rosique, Daniel Goldin e Antonio Saborit. Porto Alegre: Armed Ed. Chiavari, Maria Pace. (2000). A Baía de Guanabara: imagem e realidade. In: Salgueiro, Heliana Angoti (org.). Paisagem e 
arte. A invenção da natureza. A evolução do olhar. São Paulo: CBHA/CNPq/FAPESP (trabalhos publicados no I Colóquio Internacional de História da Arte - CBHA/CIHA), p. 25 I-258. Coelho, Mário Cézar. (2009). Victor Meirelles e a empresa de panoramas. In: Turazzi, Maria Inez (org.). Victor Meirelles. Novas leituras. Florianópolis/São Paulo: Museu Victor Meirelles/Ibran/Minc, Studio Nobel, p. I I4- I 29.

Coelho, Mário Cézar. (2008). Moldura e horizontalidade na Primeira Missa no Brasil. Esboços, I9, p. I I7-I 23.

Coelho, Mário Cézar. (2007). Os panoramas perdidos de Victor Meireles. Aventuras de um pintor acadêmico nos caminhos da modernidade. Tese de doutorado. Programa de Pós-Graduação em História/Universidade Federal de Santa Catarina. Cohen, Margareth. (2004). A literatura panorâmica e a invenção dos gêneros cotidianos. In: Charney, Leo \& Schwartz, Vanessa R. (orgs.). O cinema e a invenção da vida moderna. São Paulo: Cosac Naify, p. 259-288.

Considera, Eliane. (2000). Uma modernidade bem-comportada. O panorama da baía e da cidade do Rio de Janeiro de Victor Meireles e Langerock. In: Salgueiro, Heliana Angoti (org.). Paisagem e arte. A invenção da natureza. A evolução do olhar. São Paulo: CBHA/CNPq/FAPESP, p. 287-293.

Crary, Jonathan. (20I2). Técnicas do observador. Visão e modernidade no século XIX. Rio de Janeiro: Contraponto.

Damazio, Sylvia F. (I996). Retrato social do Rio de Janeiro na virada do século. Rio de Janeiro: EDUERJ.

Duarte, Luiz Fernando Dias. (I999). O império dos sentidos: sensibilidade, sensualidade e sexualidade na cultura ocidental moderna. In: Heilborn, Maria Luiza (org.). Sexualidade: o olhar das ciências sociais. Rio de Janeiro: Zahar, p. 2 I-30. Faria, João Roberto. (200I). Ideias teatrais. O século XIX no Brasil. São Paulo: Perspectiva/FAPESP.

França, Cristina Pierre de. (20I I). A imersão no panorama de Victor Meirelles. Artes e Ensaios, 23, nov., p. 62-7I.

Foucault, Michel. (2003). Microfísica do Poder. São Paulo: Graal. Foucault, Michel. (2002). Vigiar e punir. Petrópolis: Vozes.

Grau, Oliver. (2007). Arte virtual: da ilusão à imersão. São Paulo: Ed. Unesp/Ed. Senac. 
Heinich, Nathalie. (2008). A Sociologia da arte. Bauru, SP: EDUSC.

Hoffmann, E. T. A. (2010 [1822]). A janela de esquina de meu primo. São Paulo: Cosac Naify.

Lira, Lenice da Silva. (2000). Paisagem: construção da natureza e da cidade na arte pictórica do Rio de Janeiro, no século XIX. In: Salgueiro, Heliana Angoti (org.). Paisagem e arte. A invenção da natureza. A evolução do olhar. São Paulo: CBHA/CNPq/FAPESP, p. 259-264.

Levy, Ruth. (2008). Entre palácios e pavilhões. A arquitetura efêmera da Exposição Nacional de I908. Rio de Janeiro: EBA Publicações.

Marzano, Andrea. (2010). A magia dos palcos: o teatro no Rio de Janeiro. In: Marzano, Andrea \& Melo, Victor Andrade de (orgs.). Vida divertida: histórias do lazer no Rio de Janeiro (I830-I930). Rio de Janeiro: Apicuri, p. 97-I 23.

Mencarelli, Fernando Antonio. (I999). Cena aberta. A absolvição de um bilontra e o teatro de revista de Arthur Azevedo. Campinas: Ed. Unicamp.

Menezes, Raimundo de. (1969). Dicionário literário brasileiro (5 volumes). São Paulo: Saraiva.

Merleau-Ponty, Maurice. (1975). O olho e o espírito. In: Os pensadores. São Paulo: Abril Cultural, p. 275-30I .

Neves, Larissa de Oliveira. (2006). As comédias de Arthur Azevedo - Em busca da história. Tese de doutorado. Programa de Pos-Graduação em Teoria e História Literária/Universidade Estadual de Campinas.

Neves, Margarida de Souza. (I99I). Brasil, acertai vossos ponteiros. Rio de Janeiro: Mast.

Neves, Margarida de Souza. (I986). As vitrines do progresso. Rio de Janeiro: PUC-Rio/FINEP, mimeo.

Öelze, Berthold. (1998). A percepção das essências em Simmel. In: Öelze, Berthold \& Souza, Jesse (orgs.). Simmel e a modernidade. Brasília: Universidade de Brasília, p. 225-239. Paiva, Salvyano Cavalcanti de. (I99I). Viva o rebolado: vida e morte do teatro de revista brasileiro. Rio de Janeiro: Nova Fronteira.

Parente, André. (I999). A arte do observador. Revista Famecos, I I, dez., p I 24-I 28. 
Pavis, Patrice. (2008). Dicionário de Teatro. São Paulo: Perspectiva.

Pereira, Margareth da Silva. (20I0). O Rio de Janeiro no século XIX. Cenários, formas e virtudes de uma cidade capital. In: Pinheiro, Augusto Ivan de Freitas (org.). Rio de Janeiro: Cinco séculos de história e transformações urbanas. Rio de Janeiro: Casa da Palavra, p. I27-I6I.

Pereira, Sonia Gomes. (2009). Victor Meirelles e a Academia Imperial de Belas Artes. In: Turazzi, Maria Inez (org.). Victor Meirelles. Novas leituras. Florianópolis/São Paulo: Museu Victor Meirelles/Ibran/Minc, Studio Nobel, p. 47-63.

Peixoto, Elza Ramos. (I982). Panoramas. In: Rosa, Ângelo de Proença (org.). Victor Meirelles de Lima (I832-I903). Rio de Janeiro: Pinakotheke, p. I03-I 6.

Pesavento, Sandra Jatahy. (2008). Imagens francesas no Brasil no século XIX: paisagens e panorama. In: Leenhardt, Jacques (org.). A construção francesa do Brasil. São Paulo: Aderaldo \& Rotchschild, p. 79-I58.

Prado, Décio de Almeida. (I986). Do Tribofe à Capital Federal. In: Valença, Rachel (org.). O Tribofe. Rio de Janeiro: Nova Fronteira/Fundação Casa de Rui Barbosa, p. 255-28I. Prado, Décio de Almeida. (2008). História concisa do teatro brasileiro. São Paulo: Edusp.

Roger, Alain. (2000). La naissance du paysage em Occident. In: Salgueiro, Helina Angoti (org.). Paisagem e arte. A invenção da natureza. A evolução do olhar. São Paulo: CBHA/CNPq/ FAPESP, p. 33-40.

Rouanet, Sergio Paulo. (I988). O olhar iluminista. In: Novaes, Adauto (org.). O olhar. São Paulo: Companhia das Letras, p. I 25-I 48 .

Ruiz, Roberto. (I988). O teatro de revista no Brasil. Das origens a Primeira Guerra Mundial. Rio de Janeiro: INACEN.

Schelle, Karl Gottlob. (2001[1802]). A arte de passear. São Paulo: Martins Fontes.

Schwarz, Vanessa R. (2004). O espectador cinematográfico antes do aparato do cinema: o gosto do público pela realidade na Paris fim de século. In: Charney, Leo \& Schwarz, Vanessa R. (orgs.). O cinema e a invenção da vida moderna. São Paulo: Cosac Naify, p. 337-36o. 
Siciliano, Tatiana Oliveira. (20 I I). "O Rio que passa” por Arthur Azevedo: Cotidiano e vida urbana na Capital Federal da alvorada do século XX. Tese de doutorado. PPGAS/Museu Nacional/ Universidade Federal do Rio de Janeiro.

Simmel, Georg. (2009 [I9I3]). A filosofia da paisagem. Portugal: Coavilhã/ Universidade da Beira Interior.

Simmel, Georg. (2005 [1903]). As grandes cidades e a vida do espírito. Mana, I I/2, p. 577-59I.

Singer, Ben. (2004). Modernidade, hiperestímulo e o início do sensacionalismo popular. In: Charney, Leo \& Schwartz, Vanessa R. (orgs.). O cinema e a invenção da vida moderna. São Paulo: Cosac Naify, p. 95-I 23.

Süssekind, Flora. (1986). As revistas de ano e a invenção do Rio de Janeiro. Rio de Janeiro: Nova Fronteira/Fundação Casa de Rui Barbosa.

Velho, Gilberto. (2006). Autoria e criação artística. In: Santos, Gilda \& Velho, Gilberto (orgs.). Artifícios \& artefactos. Entre o literário e o antropológico. Rio de Janeiro: 7 Letras, p. I 35-I 42 .

Velho, Gilberto.(200I). Biografia, trajetória e mediação. In: Velho, Gilberto \& Kuschnir, Karina (orgs.). Mediação, cultura e política. Rio de Janeiro: Aeroplano, p. I3-28.

Veneziano, Neyde. (I99I). O teatro de revista no Brasil. Dramaturgia e convenções. Campinas: Ed. Unicamp.

Waizbort, Leopoldo. (2000). Ensaio. In: As aventuras de Georg Simmel. São Paulo: Edusp/Ed. 34, p. 35-74. 


\section{PINTURA E TEATRO: A PEDAGOGIA DO OLHAR N'O TRIBOFE DE ARTHUR AZEVEDO}

Resumo

Qual é a relação entre uma peça de teatro e a pintura panorâmica da cidade do Rio de Janeiro, então Capital Federal do Brasil? O Tribofe (I892), revista de ano, escrita por Arthur Azevedo, inseria como ponto de partida o panorama circular do Rio de Janeiro, pintado por Victor Meirelles e o belga Langerock, e exposto, em I89I, na Praça XV de Novembro, dentro de uma arquitetura redonda própria, a rotunda. Logo na primeira cena, o panorama era experimentado por uma família do interior, de passagem pelo Rio do final do século XIX, e sugeria que a urbe pudesse ser lida pelos visitantes e reconhecida por seus habitantes, como um quadro ou um mapa. Teatro ligeiro musicado e panorama constituíam-se em entretenimentos para um público heterogêneo, entretanto, também propunham ao "enquadrar" o olhar dos espectadores para determinado modo de ver a paisagem urbana, certa pedagogia do olhar.

\section{PAINTING AND THEATRE: TRIBOFE'S PEDAGOGY THROUGH THE GLANCE OF ARTHUR AZEVEDO}

What is the relationship between a play and a panoramic painting of the city, displayed in a rotunda placed in a central point of Brazil's federal capital? The musical theatre O Tribofe (I892) by Arthur Azevedo presented in the first scene the circular panorama of Rio de Janeiro city, painted by Meirelles and the Belgian painter Langerock. This panorama was exposed, in I89I, in the XV de Novembro Square, within a particular architecture, called rotunda. Right at the beginning of the play, the panorama was experienced by a family from backwoods of Brazil who were passing through Rio de Janeiro at the end of the nineteenth century, and suggested that the metropolis could be read by visitors and recognized by its inhabitants, such as a picture or a map. Musical theatre and panorama are forms of entertainment for heterogeneous public, however, both also training the eye for a particular way of seeing the urban landscape, in a "pedagogical" way.
Palavras-chave

Arthur Azevedo;

Cidade do Rio de Janeiro;

Metrópole;

Teatro;

Artes plásticas.

Keywords

Arthur Azevedo;

Rio de Janeiro city;

Metropolis;

Theatre;

Fine arts. 